\title{
How Age, Gender, and Class Format Relate to Undergraduate Students' Perceptions of Effective Course Assessments
}

\author{
Rosalie S. Aldrich, PhD \\ John and Corinne Graf Professor \\ Associate Professor, Department of Communication Studies \\ Indiana University East \\ Beth A. Trammell, PhD, HSPP \\ Associate Professor of Psychology, Department of Psychology \\ Indiana University East \\ Stefania Poli, MA \\ Indiana University East Alumna \\ Indiana University East \\ Sarah Potter, BS \\ Indiana University East Alumna \\ Indiana University East \\ Kourtney Garringer, BS \\ Indiana University East Alumna \\ Indiana University East
}

Students' perceptions of assessment used within the learning environment greatly influence their approach to learning. Therefore, this study aims to explore whether various student or course characteristics (age, gender, course format) impact perceptions regarding effectiveness of assessment type (e.g., exam, participation, presentation) and question format. As faculty develop their courses they may wish to consider these perceptions in order to better facilitate learning and to clearly articulate to their students the benefits of the assessment types that the students see as less effective.

Every semester, as faculty are putting together their syllabi, they undoubtedly include various assessment activities for their course (e.g., exams, presentations, writing assignments). They may include specific assignments for a variety of reasons: to promote critical thinking, to assess knowledge retention, to be consistent with common practices within the discipline, or to assess certain learning outcomes. They may also exclude assignments for other reasons, including previous negative outcomes, poor student learning, or a change in available resources. Reasons for selecting certain assignments for courses are likely to vary across disciplines and faculty.

When building course assignments and developing teaching strategies, instructors often look to best practices (Alexander, 2017; Kibble, 2017) and commonly followed guidelines (e.g., Bloom's Taxonomy). Faculty have the challenge of aligning instruction, learning, and assessment, and sometimes, faculty and students may perceive different instructional methods (e.g., lecture, flipped class room) as more or 
less effective for achieving learning outcomes (Wright, Shumway, Terry, \& Bartholomew, 2012). They may also differ regarding preference for course assessments (e.g., test, paper). More research is needed in this area because only scant research has been done to look at what types of assignments or questions students perceive effectively assess what they have learned in the class (Lizzio \& Wilson, 2013). Perceptions about assessments are related to the learning process, which is linked to academic success (Struyven, Dochy, \& Janssen, 2006). Another factor related to student performance is gender (Devaraj \& Raman, 2014). In fact, Millian, Villasenor, de la Escalera, and Carrillo (2012) stated, "It is unquestionable that gender plays a complex role in academic expectations and achievements..." (p. 152).

This study aims to further explore students' perception of assessment effectiveness concerning course assignments and question type on quizzes/exams related to student learning among different groups (male/female, traditional/nontraditional-aged, f2f/online). In the current study, the researchers specifically focused on two student characteristics, age and gender, that are generally easily accessible to the instructor prior to the start of class when syllabi are being finalized. Personal factors such as age and gender, together with the learning environment (course format), may

If different groups of students...favor different assessment types that achieve the same learning outcome, knowing that preference can more clearly inform faculty decisions regarding which types of assessment activities to include.

impact perceptions of assessment effectiveness. Some of the research on adult learning has suggested adult learners have different learning strategies (Reynolds, Stevens, \& West, 2013). If different groups of students (i.e., nontraditional-aged students; students older than 24) favor different assessment types that achieve the same learning outcome, knowing that preference can more clearly inform faculty decisions regarding which types of assessment activities to include.

\section{Quizzes, Exams, and Question Format}

\section{Literature Review}

One of the most basic ways to assess student learning in the classroom is through quizzes and exams. Testing serves multiples functions: motivates student learning, conveys instructor priorities, assesses student knowledge and comprehension, and serves as a way to assign course grades (Laprise, 2012). Middle school and high school students are known to perform better if they are given frequent quizzes over less material rather than taking fewer quizzes over more material as this gives more opportunity for feedback from the instructor (McDermott, Agarwal, D'Antonio, Roediger, \& McDaniel, 2014). It is likely this is also the case for college students.

A common question format used on both quizzes and exams is multiplechoice. Advantages of the concise, decontextualized multiple-choice questions over more complex formats, such as essays or constructed responses, are vast for both the instructor and student. In addition to the advantages, research consistently shows that students are more comfortable with this question format than essay and short answer questions (Sommer \& Sommer, 2009). There is also perceived objectivity in the grading 
process, reduced test anxiety, and increased probability of guessing that makes it a preferred assessment method for students and instructors alike (Simkin \& Kuechler, 2005; Xu, Kauer, \& Tupy, 2016). For decades, it has been suggested that students respond more favorably to multiple-choice questions compared to other types of assessments (Traub \& MacRury, 1990). However, some suggest multiple-choice questions are limited in their ability to assess comprehension or higher- order thinking (Ozuru, Briner, Kurby, \& McNamara, 2013). Others argue deeper understanding can be assessed using multiple-choice questions (Briggs, Alonzo, Schwab, \& Wilson, 2006; Crowe, Dirks, \& Wenderoth, 2008).

\section{Oral Presentations}

Another way to assess student learning is though oral presentations. Oral presentations allow students to demonstrate cognitive skills (Maes, Weldy, \& Icenogle, 1997), knowledge of course material, and ability to engage with an audience (Joughin, 2007). However, it is not uncommon for students to feel anxious or experience communication apprehension, which is defined as "an individual's level of fear or anxiety associated with either real or anticipated communication with another person or persons" (McCroskey, 1977, p. 78). Research in this area suggests that female students tend to report higher levels of public speaking anxiety than males (Shi, Brinthaupt, \& McCree, 2015). Although anxiety is associated with oral presentations, students found oral presentations valuable because it developed their professional identity and skillset (Turner, Roberts, Heal, \& Wright, 2013).

\section{Research Projects, Writing Assignments, and Participation Points}

Along with quizzes, exams, and oral presentations, it is common for faculty to include other types of assignments to gather information about student learning. However, evaluating students' perception about other assessment formats, such as research projects, writing assignments, and participation points, are less prolific. A recent posting on Faculty Focus explored the importance of appropriate distribution of points across a variety of assignments to give ample and different opportunities for students with different learning styles but did not offer empirical support for the preferences of students (Weimer, 2012). Rather, the aforementioned article offered suggestions about the importance of consulting with other faculty and students themselves about point distributions and assessment strategies.

While there is support for the benefits of research projects from both the faculty and students (Hunter, Laursen, \& Seymour, 2007), what is less clear is if students perceive this type of assessment as measuring what they have learned in a specific course. Similarly, research on students' beliefs about perceived effectiveness of written assignments is also limited.

Participation points are also often included as assessment activities for undergraduate courses as they provides important feedback to the instructor about student learning and the effectiveness of instruction (Clayton \& Woodard, 2007). Previous research has noted that students generally do believe that participation in class is an essential part of effective learning (Fritschner, 2000), but there are many 
reasons why students do not participate or participate less frequently than perhaps they should (Rocca, 2010). While there has been some research about certain personality qualities of students that may make them more or less likely to participate in class (Sidelinger, 2010), there is little, if any, research about students' beliefs that this is an effective way to measure learning.

Beyond assessment type, no formal research could be found on what students believe should be the breakdown of points awarded for various assignments. This information is important for both students and faculty to gain understanding of where students place the most value, and possibly effort. This understanding may further help faculty engage students in learning if assessments are weighted in such a way that they align with student expectations.

Therefore, the current study aims to better understand students' perceptions of effective assessments for measuring student learning and desired point distribution across assignments. The literature on student age, gender, and course format regarding student preferences for course assessment is inconsistent and somewhat lacking; therefore, we put forth the following research questions:

RQ1: Are there differences between men and women in their perception of effectiveness of various academic assessments?

RQ2: Are there differences between traditional-and nontraditional-aged students and perception of effective academic assessments?

RQ3: Are there differences between course format (online, face-to-face, hybrid) and perception of effective academic assessments?

RQ4: What do students desire regarding point distribution across class assessments?

\section{Participants}

\section{Method}

The sample was composed of 121 participants, 82 females $(67.8 \%)$ and 39 males $(32.2 \%)$, ranging in age from 18 to $52(M=24.18, S D=7.61)$. The majority of the sample was Caucasian $(n=115,95 \%)$. Students answered the question, "Do you take more in-person classes, online, or hybrid classes?" Of the participants, 58 (47.9\%) took more on-campus classes, $48(39.7 \%)$ took more online classes, and $14(11.6 \%)$ were enrolled mostly in hybrid classes. Eighty participants were identified as "traditionalaged" in the 18-23 year-old age group $(M=3.89, S D=.99)$ and 36 were identified as "nontraditional-aged" in the 24 years-old and older age group $(M=3.86, S D=.76)$.

\section{Procedures}

This study was approved by the university's Institutional Review Board. Participation was voluntary. Undergraduate students at a regional Midwest university participated in an online survey to fulfill a course research requirement where an alternative assignment was available if they chose not to participate. Other students participated to receive extra credit (this distinction depended on the course instructor). Participants did not receive compensation. The participants were instructed to visit a web address where they completed informed consent and an online survey. 


\section{Instrumentation}

Participants were asked to respond to 18 questions that centered on what the student believed was the most effective way of assessing student learning. First, participants were asked to respond to the following two questions on a 5-point Likert scale ranging from strongly disagree to strongly agree: "Exams are an effective means of assessing what a student has learned in the course" and "Quizzes are an effective means of assessing what a student has learned in the course." Next, participants were asked to answer questions on a 5-point Likert scale ranging from strongly disagree to strongly agree about the types of questions effective exams and quizzes have. For example, "The most effective exams have essay questions." Specifically, the question types that were identified were essay questions, short answer, multiple-choice, fill-inthe blank, and true/false. Students were next asked to identify which course assignments do the best job of showing what they have learned on a 5-point Likert scale ranging from strongly disagree to strongly agree. The specific assignments were research projects, oral presentations, weekly journals, small writing assignments (under two pages), longer writing assignments (more than 2 pages), and participation points. Next, students identified the weighting they would prefer to be given to exams, quizzes, and course work and together the percentage had to equal 100 in order to move on. Finally, demographic data was collected.

\section{Results}

In order to test RQ1: Are there differences between men and women in their perception of effectiveness of various academic assessments?, first a one-way analysis of variance (ANOVA) was used to determine if males and females differed in their belief that exams and quizzes are effective. There was no significant difference between how males $(M=3.76, S D=.97)$ and females $(M=3.95, S D=.84)$ viewed quizzes $F(1,116)=1.15$, $p=.29$ and exams $F(1,116)=.07, p=.80$ (males, $M=3.76, S D=1.05$; females, $M=3.81, S D=.92$ ). Additionally, because all means were above the mid-point, this suggests that both males and females view quizzes and exams as effective measures of what a student has learned in the course.

To determine if males and females differed in what types of questions they believe are effective on quizzes, a one-way ANOVA was conducted. There were no significant differences between males and females and the types of questions they believe are effective on quizzes (see Table 1 on p. 123). There were, however, two significant differences between males and females regarding the types of questions they believe are effective on exams: 1$)$ females $(M=3.61, S D=1.09)$ thought effective exams include essay questions, $F(1,116)=8.22, p<.01$, whereas males did not $(M=2.95$, $S D=1.36)$; and 2) females $(M=4.06, S D=.86)$ thought short answer questions on exams were more effective, $F(1,116)=11.30, p<.001$ than males $(M=3.45, S D=1.10)$.

Again, a one-way ANOVA was conducted to examine if males and females differed in what assignments they believe effectively do the best job of demonstrating student learning. There was one significant difference between males $(M=4.11, S D=.86)$ and females $(M=3.56, S D=1.10)$ for participation points, $F(1,116)=7.14, p<.01$. There were also two assignments approaching significance: 1 ) weekly journals, $F(1,116)=3.24$, $p=.07$, with females finding them more effective $(M=3.44, S D=.97)$; and 2$)$ research 
projects, $F(1,116)=3.66, p=.06$, with males $(M=3.71, S D=.90)$ finding them more effective than females $(M=3.34, S D=1.03)$.

Table 1

ANOVA Results for Effective Question Types on Quizzes

\begin{tabular}{|c|c|c|c|c|c|c|}
\hline Question Type & df1 & df2 & $F$ & $p$ & Mean & SD \\
\hline \multirow{2}{*}{$\begin{array}{l}\text { Essay } \\
\text { Questions }\end{array}$} & 1 & 116 & 1.53 & .22 & Male, $\mathrm{M}=2.84$ & .21 \\
\hline & & & & & Female, $\mathrm{M}=3.14$ & .13 \\
\hline \multirow[t]{2}{*}{ Short Answer } & 1 & 116 & 2.80 & .10 & Male, $\mathrm{M}=2.84$ & .21 \\
\hline & & & & & Female, $\mathrm{M}=3.14$ & .13 \\
\hline \multirow{2}{*}{$\begin{array}{l}\text { Multiple- } \\
\text { Choice }\end{array}$} & 1 & 116 & .16 & .69 & Male, $M=4.21$ & 1.07 \\
\hline & & & & & Female, $\mathrm{M}=4.28$ & .66 \\
\hline \multirow{2}{*}{$\begin{array}{l}\text { Fill-in the } \\
\text { Blank }\end{array}$} & 1 & 116 & 2.39 & .13 & Male, $M=3.47$ & 1.25 \\
\hline & & & & & Female, $M=3.81$ & 1.05 \\
\hline \multirow[t]{2}{*}{ True/False } & 1 & 116 & .47 & .49 & Male, $M=3.82$ & 1.23 \\
\hline & & & & & Female, $\mathrm{M}=3.96$ & 1.01 \\
\hline
\end{tabular}

To test RQ2: Are there differences between traditional- and nontraditional-aged students and perception of effective academic assessments?, a one-way ANOVA examined whether there were any differences between traditional- and nontraditional-aged students in their beliefs regarding the effectiveness of quizzes and exams to assess student learning. There was not a significant difference between traditional $(M=3.89$, $S D=.94)$ and nontraditional $(M=3.94, S D=.58)$ students. Both groups reported quizzes as an effective way to assess student learning, $F(1,114)=.08, p=.74$. There was also not a significant difference between the two groups regarding the effectiveness of exams, $F(1,114)=.11, p=.75$, traditional $(M=3.80, S D=1.00)$, nontraditional $(M=3.86, S D=.76)$.

Next, a one-way ANOVA tested group differences to determine if traditionaland nontraditional-aged students preferred different types of questions on quizzes. There were significant differences for two of the five question types: essay questions, $F(1,114)=4.18, p<.05$, traditional $(M=2.90, S D=1.23)$, nontraditional $(M=3.39, S D=1.10)$; multiple-choice questions, $F(1,114)=4.96, p<.05$, traditional $(M=4.39, S D=.72)$, nontraditional $(M=4.06, S D=.79)$. Nontraditional-aged students thought essay questions were somewhat effective at assessing learning where traditional-aged students did not. While both nontraditional and traditional students believed multiple-choice questions were effective ways to assess learning, traditional-aged students rated them as more effective than nontraditional-aged students.

Again, a one-way ANOVA was used to assess if there was a difference between traditional and nontraditional students and types of questions they see as effective on exams. There were no significant differences found although the same two question formats that were significant for quizzes (essay and multiple-choice) were 
approaching significance for exams; essay questions, $F(1,114)=2.89, p=.09$, traditional $(M=3.29, S D=1.23)$, nontraditional $(M=3.69, S D=1.09)$.

Finally, coursework preferences were examined to determine if there were group differences between traditional- and nontraditional-aged students using a oneway ANOVA. There was a significant difference between traditional $(M=3.70, S D=.96)$ and nontraditional students $(M=4.08, S D=.60), F(1,114)=4.86, p<.05$ related to small writing assignments, where nontraditional students more strongly agreed that shorter writing assignments (less than 2 pages) are effective at showing what students learned. A second significant difference existed for longer writing assignments, defined as more than 2 pages, $F(1,113)=7.25, p<.01$. Traditional students $(M=3.10, S D=1.05)$ again did not feel as strongly as nontraditional students $(M=3.64, S D=.87)$ that longer writing assignments best assessed student learning.

To address RQ3: Are there differences between course format (online, face-to-face, hybrid) and perception of effective academic assessments?, a one-way ANOVA was used to determine if there was a difference between $\mathrm{f} 2 \mathrm{f}(n=56)$, online $(n=48)$, and hybrid $(n=14)$ courses and student beliefs about quiz and exam effectiveness for measuring student learning. No significant differences were found for quizzes, $F(2,115)=.80, p=.45$, $\mathrm{f} 2 \mathrm{f}(M=3.88, S D=.90)$, online $(M=3.98, S D=.86)$, and hybrid $(M=3.57, S D=.96)$. Students in all formats found quizzes as a moderately effective way to assess student learning. The same was conducted for exams, and again no significant differences were found, $F(2,115)=.67, p=.52, \mathrm{f} 2 \mathrm{f}(M=3.77, S D=1.01)$, online $(M=3.90, S D=.88)$, hybrid $(M=3.57$, $S D=1.02)$. Again, students across formats found exams moderately effective at assessing student learning.

Differences between $\mathrm{f} 2 \mathrm{f}$, online, and hybrid in relation to question type on quizzes and exams was tested with a one-way ANOVA. There were no significant differences found for quizzes or exams for any of the question types (essay, short answer, multiple-choice, fill-in the blank, true/false).

A one-way ANOVA was conducted to compare the course format and type of assessment students see as effective. The only significant difference was for oral presentation, $F(2,114)=4.10, p<.05$. Follow-up comparisons using the Tukey HSD test on the oral presentation item indicated that the mean score for the hybrid class format $(M=2.36, S D=1.01)$ significantly differed from the on-campus class format $(M=3.33$, $S D=1.11), p<.01$. No other significant differences were found for course format and assessment preference to show student learning.

In order to address RQ4: What do students desire regarding point distribution across class assessments?, frequencies were calculated. See Table 2 where mean, median, mode, and standard deviation are presented. Overall, students would prefer that course work count for more of their overall grade than exams or quizzes.

Table 2

Frequencies for Desired Percentage Distribution of Graded Assessments

\begin{tabular}{lcccc}
\hline & Mean & SD & Median & Mode \\
\hline Exams & $31.86 \%$ & 13.15 & 30 & 25 \\
Quizzes & $24.34 \%$ & 10.27 & 25 & 25 \\
Course Work & $44.01 \%$ & 17.87 & 50 & 50 \\
\hline
\end{tabular}




\section{Discussion}

This study examined students' perceptions of the effectiveness of various assessments across groups. Students' perceptions of assessments are important as they can influence learning and student engagement with the course material (Gibbs, 2006). Implications of this are particularly interesting for faculty members that teach classes that are male- or female-dominated. Results from our gender analysis suggest females believe exams that allow further explanation of the response (essay and short answer questions) are more effective, whereas males believe this to be less true. Males believed participation points were more effective. This difference could be conceptualized as females preferring to express their knowledge in writing, whereas males may be more likely to show their knowledge (Birenbaum \& Feldman, 1998). Some research suggests this difference exists because of the tendency for male students to dominate the classroom discussion (Caspi, Chajut, \& Saporta, 2008; Crombie, Pyke, Silverthron, Jones, \& Piccinin, 2003), allowing them the opportunity to adequately demonstrate knowledge and learning, and providing less of a chance for female students to do the same. A third explanation may be related to public speaking anxiety. As mentioned in the literature review, female students reported experiencing higher levels of public speaking anxiety than males (Shi et al., 2015) and participating in class discussions is an informal form of public speaking. There are likely other factors such as course level, course content, instructor personality, etc. that contribute to these findings, which seems ripe for further exploration.

When exploring traditional- and nontraditional-aged students, traditional students did not perceive writing assignments to be as effective as nontraditional students. This may be related to nontraditional students having more experience with writing, both in academic settings and professional ones, than traditional students, who in more recent years have focused much of their secondary education preparing for and taking standardized tests. Students reported that only $9 \%$ of their university and $13 \%$ of their high school tests were essay tests, and a majority of their tests were all multiple-choice (Sommer \& Sommer, 2009). This perception difference between traditional and nontraditional students regarding how well writing assignments assess what the student has learned is an interesting one and should be explored further in future research.

Both traditional and nontraditional students found multiple-choice questions to be effective measurement of learning. However, traditional students indicated they found these types of questions to be more effective at measuring student learning than nontraditional students. Previous research supports that students prefer multiplechoice questions (Simkin \& Kuechler, 2005; Xu, et al., 2016), and this study goes a step further indicating students of all ages, perceive multiple-choice questions to be an effective measurement of their learning.

When exploring class format (online, $\mathrm{f} 2 \mathrm{f}$, hybrid), the researchers only found one significant difference - $\mathrm{f} 2 \mathrm{f}$ students believed oral presentations were more effective to show learning in a course than those in a hybrid class format. This may suggest those students who engage in online learning (hybrid or all online) formats have personal characteristics (e.g., high communication apprehension) that differ from those students who take f2f courses. Another plausible explanation might be that some 
online learners who have low technology self-efficacy struggle to produce high quality presentations (e.g., content rich, visually/audio poor); therefore, feeling the oral presentation was not an effective measure of what they learned. An additional potential factor for this difference may be that students are unaware of online presentations as an option through online or hybrid learning. In fact, students, and even faculty, may believe that the course modality (online/hybrid) eliminates oral presentations as a possibility. This is another area that should be looked at further.

Faculty members may consider the differences that emerged in this study to guide their teaching and/or course design. One potential way to match students' assessment preferences with course learning outcomes is to offer the students choice of assessment type. For example, the purpose of an assignment is the same for all (e.g., presentation introducing self to the class), but the students are given choices of how to achieve the objectives (e.g., speech, video with photos or videos set to music, multimedia poster).

This is clearly not an option for every learning assessment, nor is it practical to align every assessment with students' preferences. Additionally, it is not beneficial to students as they may prefer assessments they are used to, not good at, or even what best measures learning. It becomes a balance between student preferences and expectations and best practices for measuring student learning.

This study has several limitations. Due to the disproportionate number of female $(67.8 \%)$ and Caucasian student respondents $(95 \%)$, a limitation of the study includes low external validity of the results. As with many survey studies, a sample was used and data was collected at only one point in time. It would be beneficial to collect data from a randomly selected sample and follow them longitudinally through their college careers to examine if their perceptions about assessment effectiveness shift over time or across courses. When asked about point distribution, students were only asked to rate quizzes, exams, and other coursework. Further investigation is needed to examine how students may prefer that "other" coursework (e.g., presentations, writing assignments) to be distributed as well. There were many types of assessment not addressed in this survey, such as case studies and/or problem scenarios. It will be important for future researchers to clearly define each assessment type, although most terms used here seem self-evident (e.g., multiple-choice question), others may not (e.g., exam vs. quiz). It is important for students to be able to understand the distinction while answering the survey questions. This is an exploratory study and other types of assessments should be defined and examined in future studies.

Despite the described shortcomings, this study aims to fill a gap in the scarcity of research exploring differences in student perception of assessment methods from different student groups (i.e. traditional vs. nontraditional) enrolled in different class formats (f2f, online, hybrid), with different student characteristics in terms of gender and age. Further research is necessary to expand these results beyond our limited sample and provide additional insights about students' assessment expectations and preferences. 


\section{References}

Alexander, R. C. (2017). Best practices in online teaching across disciplines. Fairfax, VA: George Mason University Press.

Birenbaum, M., \& Feldman, R. A. (1998). Relationships between learning patterns and attitudes towards two assessment formats. Educational Research, 40, 90-98.

Briggs, D. C., Alonzo, A. C., Schwab, C., \& Wilson, M. (2006). Diagnostic assessment with ordered multiple-choice items. Educational Assessment, 11, 33-63.

Caspi, A., Chaju, E., \& Saporta, K. (2008). Participation in class and in online discussions: Gender differences. Computers and Education, 50, 718-724.

Clayton, M. C., \& Woodard, C. (2007). The effect of response cards on participation and weekly quiz scores of university students enrolled in introductory psychology courses. Journal of Behavioral Education, 16, 250-258.

doi: 10/1007/s10864-007-9038

Crombie, G., Pyke, S. W., Silverthron, N., Jones, A., \& Piccinin, S. (2003). Students' perception of their classroom participation and instructor as a function of gender and context. Journal of Higher Education, 74, 51-76.

Crowe, A., Dirks, C. \& Wenderoth, M. P. (2008). Biology in bloom: Implementing Bloom's Taxonomy to enhance student learning in biology. CBE Life Sciences Education, 7, 368-381.

Devaraj, N., \& Raman, J. (2014). The effective of student learning styles, race, and gender on learning outcomes: The case of public goods, Journal of Learning in Higher Education, 10, 37-48.
Fritschner, L. M. (2000). Inside the undergraduate college classroom. Journal of Higher Education, 71, 342-362.

Gibbs, G. (2006). How assessment frames student learning. In C. Bryan \& K. K. Clegg (Eds.), Innovative Assessment in Higher Education (pp. 23-36). London, England: Routledge.

Hunter, A. B., Laursen, S. L., \& Seymour, E. (2007). Becoming a scientist: The role of undergraduate research in students' cognitive, personal, and professional development. Science Education, 91, 3674 .

Joughin, G. 2007. Student conceptions of oral presentations. Studies in Higher Education 32, 323-336.

doi: 10.1080/03075070701346873.

Kibble, J. D. (2017). Best practices in summative assessment. Advances in Physiological Education, 41, 110-119. doi: 10.1152/advan.00116.2016

Laprise, S. L. (2012). Afraid not: Student performance versus perception based on exam question format. College Teaching, 60, 31-36.

doi: 10.1080/87567555.2011.627575

Lizzio, A., \& Wilson, K. (2013). First-year students' appraisal of assessment tasks: Implications for efficacy, engagement and performance. Assessment and Evaluation in Higher Education, 38, 389406. doi: 10.1080/02602938.2011.637156

Maes, J. D., Weldy, T. G., \& Icenogle, M. L. (1997). A managerial perspective: Oral communication competency is most important for business students in the workplace. Journal of Business Communication, 34, 67-80. 
McCroskey, J. C. (1977). Oral Sidelinger, R. J. (2010). College student communication apprehension: A involvement: An examination of student summary of recent theory and research. characteristics and perceived instructor Human Communication Research, 4, 78-96. communication behaviors in the McDermott, K. B., Agarwal, P. K., D'Antonio, L., Roediger, H. L., III, \& McDaniel, M. A. (2014). Both multiplechoice and short-answer quizzes enhance later exam performance in middle and high school classes. Journal of Experimental Psychology: Applied, 20, 3-21.

Millan, V., Villasenor, E. A., de la Escalera, N. M., \& Carrillo, H. (2012). Gender differences in academic performance at UNAM. Resources for Feminist Research, 34(1), 149-165.

Ozuru, Y., Briner, S., Kurby, C. A., \& McNamara, D. S. (2013). Comparing comprehension measured by multiplechoice and open-ended questions. Canadian Journal of Experimental Psychology, 67, 215-227.

Reynolds, C., Stevens, D. D., \& West, E. (2013). I'm in a professional school! Why are you making me do this? A crossdisciplinary study of the use of creative classroom projects on student learning. College Teaching, 61, 51-59.

doi: 10.1080/87567555.2012.731660

Rocca, K. A. (2010). Student participation in the college classroom: An extended multidisciplinary literature review. Communication Education, 59, 185-213.

Shi, X., Brinthaupt, T. M., \& McCree, M. (2015). The relationship of self-talk frequency to communication apprehension and public speaking anxiety. Personality and Individual Differences, 75, 125-129.

doi: 10.1016/j.paid.2014.11.023 classroom. Communication Studies, 61, 87-103.

Simkin, M. G., \& Kuechler, W. L. (2005). Multiple-choice tests and student understanding: What is the connection? Decision Sciences Journal of Innovative Education, 3, 73-98.

Sommer, R., \& Sommer, B. A. (2009). The dreaded essay exam. Teaching of Psychology, 36, 197-199.

doi: $10.1080 / 00986280902959820$

Struyven, K., Dochy, F., \& Janssens, S. (2006). Students' perceptions about new modes of assessment in higher education: A review. In M. Segers, F. Dochy, \& E. Cascallar (Eds.), Optimising new modes of assessment: In search of qualities and standards (pp. 171-223). Netherlands: Springer.

Traub, R. E., \& MacRury, K. (1990). Multiple-choice vs. free response in the testing of scholastic achievement. Unpublished manuscript, The Ontario Institute for Studies in Education. Published in German in K. Ingenkam \& R. S. Jager (Eds.) Tests und trends 8: Jahrbuch der Padagogischen Diagnostik (pp. 128-159). Weinheim \& Basel: Beltz Verlag.

Turner, K., Roberts, L., Heal, C. \& Wright, L. (2013). Oral presentation as a form of summative assessment in a master's level PGCE module: The student perspective. Assessment and Evaluation in Higher Education, 38, 662673. doi: 10.1080/02602938.2012.680016 
Weimer, M. (2012). Distributing points and percentages across assignments and activities. Retrieved from http://www.facultyfocus.com/articles/te aching-professor-blog/distributingpoints-and-percentages-acrossassignments-and-activities/
Wright, G., Shumway, S., Terry, R., \& Bartholomew, S. (2012). Analysis of five instructional methods for teaching sketchpad to junior high students. Journal of Technology Education, 24, 54-72.

Xu, X., Kauer, S., \& Tupy, S. (2016). Multiple-choice questions: Tips for optimizing assessment in-seat and online. Scholarship of Teaching and Learning in Psychology, 2, 147-158.

Rosalie S. Aldrich has been teaching at the university level for 11 years, including seven years online, primarily in the areas of health communication, interpersonal communication, gender communication, and research methods. Dr. Aldrich holds an administrative position as Lead Faculty for Online Programs in the Department of Communication Studies and is also a certified peer reviewer for Quality Matters. She has taught over 30 online courses and has also developed and designed several. Her research interests include the scholarship of teaching and learning online and face-to-face as well as suicide prevention and intervention.

Beth Trammell has been teaching psychology classes online and face-to-face for the last five years, focusing on active learning strategies and integrating assessment into the classroom. Beth regularly incorporates high-impact practices and servicing learning to deepen learning opportunities for her students. She also uses examples from her private practice to help students apply the material from class to their everyday lives.

Stefania Poli has a BA degree in Education from the University of Parma, Italy and a Master's degree in Education from Indiana University. She has been teaching in various institutions in the U.S.A. and Switzerland; after moving to Switzerland and earning a BS degree in Psychology, Stefania specialized in neurofeedback/biofeedback therapy. She now works in her private practice, where she integrates her technical knowledge with the broader humanistic perspective acquired during her academic path.

Sarah Potter is a 2017 graduate from Indiana University East. She has her Bachelor's Degree in Psychology. She currently works as a Human Resources Coordinator and plans on pursuing her Master's Degree in the fall of 2018.

Kourtney Garringer is an Indiana University East undergraduate student in the Psychology department. 